\title{
Landslide Induced Displacement and Relocation Options: A Case Study of Owner Driven Settings in Sri Lanka
}

\author{
Anuradha Senanayake ${ }^{1, *}$, Nishara Fernando ${ }^{1}$, Maduri Wasana ${ }^{2}$, Dilanthi Amaratunga ${ }^{3}$, Richard Haigh ${ }^{3}$, \\ Chamindi Malalgoda ${ }^{3}$ and Chathuranganee Jayakody ${ }^{3}$ iD
}

check for

updates

Citation: Senanayake, A.; Fernando,

N.; Wasana, M.; Amaratunga, D.;

Haigh, R.; Malalgoda, C.; Jayakody, C. Landslide Induced Displacement and Relocation Options: A Case Study of Owner Driven Settings in Sri Lanka. Sustainability 2022, 14, 1906. https:// doi.org/10.3390/su14031906

Academic Editors: William Frodella and Michalis Diakakis

Received: 31 October 2021

Accepted: 18 January 2022

Published: 8 February 2022

Publisher's Note: MDPI stays neutral with regard to jurisdictional claims in published maps and institutional affiliations.

Copyright: (c) 2022 by the authors. Licensee MDPI, Basel, Switzerland. This article is an open access article distributed under the terms and conditions of the Creative Commons Attribution (CC BY) license (https:// creativecommons.org/licenses/by/ $4.0 /)$.
Department of Sociology, University of Colombo, Colombo 999011, Sri Lanka; nishara.fernando@soc.cmb.ac.lk 2 Social Policy Analysis and Research Centre, Colombo 999011, Sri Lanka; maduri.wasana@gmail.com

3 Global Disaster Resilience Centre, University of Huddersfield, Huddersfield HD1 3DH, UK; D.Amaratunga@hud.ac.uk (D.A.); R.Haigh@hud.ac.uk (R.H.); C.Malalgoda@hud.ac.uk (C.M.); C.Jayakody2@hud.ac.uk (C.J.)

* Correspondence: anuradha@soc.cmb.ac.lk
Abstract: Disaster induced displacement is one of the most frequent phenomena occurring in the contemporary world and has been aggravated by factors such as climate change. With the systematic interpretation of disaster risks, planned relocation has been recognized as a durable solution for post-disaster reconstruction and disaster mitigation. Planned relocation initiatives that have been executed as post-disaster reconstruction initiatives in Sri Lanka have mainly followed donor driven and owner driven approaches. This study is a comparative analysis of the status quo of owner driven relocation options that were implemented after the landslide which took place in 2016 in the $X$ District of Sri Lanka. Two research fields were selected based on the two owner driven options as part of the selected case study: Government Resettlement Sites and Individual Resettlement Sites. This exploratory study utilizes both secondary and primary data. A purposive sample of ten households was selected from each setting to conduct in-depth interviews. Furthermore, five structured interviews with key informants were conducted using an expert sample. Secondary data were collected based on the concepts of relocation and satisfaction of housing. The findings suggest that the respondents were satisfied with the housing units in both settings despite concerns in relation to the suggested plans of the housing units. Furthermore, common concerns were raised in terms of delays and issues in fund management in construction of houses. However, there was a drastic disparity in terms of other infrastructural, public, and neighborhood facilities in the two settings. Hence, this study suggests the need for an overall management and monitoring strategy for all owner driven relocation options.

Keywords: disaster induced displacement; housing; owner driven; relocation

\section{Introduction}

Disasters are a frequent phenomenon in the world and climate change has been recognized as a risk multiplier for disaster risks [1]. Despite the fact that the year 2020 is known for its novel biological hazard, it has been recognized as a year that was dominated by disasters that were driven by climate change [2]. In 2020, a total of 389 extreme weather events were reported where 15,080 people were killed and 98.4 million people were affected [3]. Furthermore, 2020 is also highlighted as a vital year in the disaster discourse compared to 2016 as it was the world's hottest year and heat waves were recorded as the topmost disaster that induced mortality in the UK, France, Belgium, and Netherlands in 2020 [3]. Floods were the most common disaster in 2020 with 201 events recorded worldwide causing a total of $41 \%$ deaths [4]. On the other hand, storms have affected the highest number of people amounting to 45.5 million in number [4].

As per the Internal Displacement Monitoring Centre and Norwegian Refugee Council [5], disaster induced displacement has been ranked as the most common mode of 
displacement with 30.7 million people being displaced due to a natural hazard in the year 2020. In terms of the global context of disaster induced displacement in 2020, East Asian and Pacific regions have ranked the highest in disaster induced displacement with a 30.3\% proportion of the global statistics [5]. The Asia Pacific region has been a vital geographical location in terms of disaster induced displacement. Furthermore, $80 \%$ of the global disaster induced displacement cases (approximately 187 million cases) have been reported from the Asia Pacific region between 2008 to 2018 [6].

These disasters have direct and indirect impacts such as mortality, economic loss, and damage to housing, local infrastructure, livestock, and crops [7]. In the early 1990s, the Disaster Risk Reduction discourse came to the forefront of discussion with the objective of reduction, through concentrated international action when handling disaster risks such as the loss of life, property damage, and socio-economic disruption caused by natural disasters [8]. The latest framework which addresses the Disaster Risk Reduction discourse, the Sendai Framework for Disaster Risk Reduction (SFDRR) 2015-2030 has a broader and a more people-centered, preventive approach to disaster risks [9]. The paragraph $27(\mathrm{~K})$ of SFDRR recognizes the need for having governing structures that address prevention or relocation, of human settlements in disaster risk-prone zones (where possible). Planned relocation, however, is generally considered a last resort given the significant challenge of maintaining people's wellbeing, dignity, livelihoods, cultural heritage, and rights throughout the process [10].

In this context, planned relocation has been recognized as a response which compliments Disaster Risk Reduction [11]. Researches have been conducted on permanent housing as an important disaster recovery effort where many have assessed the successes, failures, and good practices of such initiatives [12]. Different disaster contexts around the world tend to utilize several approaches in post disaster relocation housing constructions. India has utilized methods such as the owner-driven approach, the subsidiary housing approach, the participatory housing approach, the contractor-driven approach, and the contractor-driven approach in 2001 for reconstruction of housing units which were destroyed in an earthquake that took place in Gujarat [13]. On the other hand, owner driven and donor driven approaches were utilized for post Tsunami housing reconstructions in Sri Lanka [14]. In the donor-driven approach, donors (of private, government and non-government sectors) both local and international, build houses at relocation sites for families who lived within the disaster-prone areas. On the other hand, in the owner-driven approach, damaged (fully or partially) houses located outside the disaster prone areas are repaired/reconstructed at the same premises by owner's themselves [15].

This study is based on Sri Lanka within the above-mentioned context. Sri Lanka is a country that is known to be affected by various hazards such as flooding, landslides, cyclones, and droughts [16]. During the period 1990-2018, Sri Lanka recorded the highest number of $58 \%$ proportion of flooding incidents [17]. When considering the context of landslide hazard, its constant evolution has been identified between the period of 1952-2020 with a significant increase in the last 20 years [18]. In the year 2020, 101,778 families and 363,399 people were affected and 62 deaths were reported due to disasters [19]. Based on this disaster context, planned relocation has been used as a disaster risk reduction strategy in Sri Lanka [20].

Several studies have been conducted comparing owner driven and donor driven relocation approaches $[14,21]$. However, this is one of the first studies which explores the owner driven relocation option as a post disaster induced recovery strategy in Sri Lanka. Given that it is evident that utilizing relocation options in post-disaster planned relocation is a well-known global practice, this study will contribute towards the existing knowledge in the field of planned relocation as a post disaster recovery strategy. While this study will be a narrative of the Global South, it will add to the global discourse of building back communities better post disaster displacement through planned relocation options.

Considering the above-mentioned facts, this study is an attempt to address the following research problem: what is the status quo of the owner driven relocation options that 
were implemented post landslide in the X District of Sri Lanka in the year of 2016? Hence, this research revolves around the main objective of comparing the status quo of owner driven relocation options that was implemented after the landslide which took place in 2016 in the X District of Sri Lanka. The following sub objectives were utilized to attain the said main objective:

1. To investigate about the relocation process in general in the selected case study

2. To evaluate the status quo of the housing units in the selected owner driven relocation settings

3. To inquire the status quo of the infrastructure facilities in the selected owner driven relocation settings, and

4. To examine the role of social capital in the selected owner driven relocation settings.

\section{Materials and Methods}

Having explained the background of this present study, this section explains the conceptual framework and the methodology of the present study.

\subsection{Concepts}

The conceptual framework of this study revolves around displacement, disaster, and relocation. This section elaborates on the said concepts and the relevant conceptual frameworks that will be utilized in the present study. The said frameworks are, Stress and Settlement Process of involuntary resettlement [22], Impoverishment Risks and Reconstruction Model for Resettling Displaced Population [23], and the Model of Residential Satisfaction of Public Low Cost Housing [24].

When evaluating conceptual frameworks relevant to the present study, Scudder's [21] introduction of the Stress and Settlement Process on involuntary resettlement is vital. This considers the physiological, psychological, and socio-cultural stress that people have to deal with throughout an involuntary resettlement process. He further suggests that such stress could be overcome through a proper resettlement plan and further perceives that relocation is a long-term process consisting of the following four stages: planning and recruitment, coping and adjustment, community formation and economic development, and handing over and incorporation [21].

Cernea [22] took this stance one step further through the conceptual framework of Impoverishment Risks and Reconstruction Model for Resettling Displaced Population. According to this model, people face risks of economic, social, and cultural impoverishment when they resettle in a new location and prevention is a challenge for officers in charge of the resettlement plan. This model could be used as a planning and monitoring tool. This model discusses eight possible risks that could influence the resettlement process rather than considering different stages. These risk patterns were identified based on the comparison of empirical studies [24]. The eight risks are landlessness, joblessness, homelessness, marginalization, food insecurity, increased morbidity and mortality, loss of access to common property and services, and social disarticulation.

In terms of housing, the model of residential satisfaction of public low cost housing formulated by Mohit, Ibrahim, and Rashid (2010) [23] is important. According to this theory, satisfaction with low income housing primarily depends on the management of the housing's facilities and surroundings [23]. Residential satisfaction is considered through the relationship between the objective and subjective attributes of a residential environment. Sheltered and non-sheltered components are used to evaluate residential satisfaction which has been termed as the "residential satisfaction bundle," representing the objective attributes of the residential environment. Those components include the following forty-five variables:

1. Sheltered components:

a. Dwelling unit features: floor plan of dwelling unit (kitchen, toilet, etc.) and ventilation 
b. Dwelling unit support services: support services outside the dwelling unit for example corridors, staircase, balconies, electricity, water, sewerage, drainage, telecommunication, lifts, and fire-fighting system [21].

2. Non-sheltered components:

a. Public facilities: open space, play areas, parking, prayer and multipurpose halls, perimeter roads, pedestrian walkways, public phones, local shops, and food stalls

b. Social environment: noise, crime, accidents, security, and community relations, and

c. neighborhood facilities: distance to town center, school, police station, hospital, market, shopping centers, public library, religious building, bus, and taxi stations [23].

Apart from the above-mentioned frameworks, in some cases, relocation can be a successful adaptive strategy with a solid basis of policies that considers the overall impact of environment degradation [25].

This relocation should be compared with the concept of "environmental mobility" which is defined as local, voluntary moves undertaken in the face of imminent environmental risk. [26]. The impacts of climate change vary from one context to another. It has been reported that where more people may be left without the resources to migrate or trapped in risky environments, others may be compelled to migrate more frequently, to farther destinations, or more permanently, in search of natural resources and to find employment [27]. However, in the context of this study, human mobility of the relocates were more or less planned following the occurrence of the extreme weather events which lead to a mass displacement.

\subsection{Methods}

This section discusses the research field, the relocation project, and the methods utilized in the present study.

The study is based on a post disaster relocation project executed in the $\mathrm{X}$ District. The $X$ district has been ranked among the top 5 districts with the highest number of people affected and the second highest number of deaths recorded due to disasters in Sri Lanka. The $X$ district has recorded affliction of 2643 families and 8768 individuals and 6 people killed due to disasters in 2020 [17].

As per the disaster profile of the $X$ district, the year 2016 was a turning point due to the heavy rainfall in the month of May. 17 May 2016 marked a dark day in the history of disaster discourse in Sri Lanka when a landslide took place in the X district [28]. It has been estimated that 301,602 people were affected by this disaster where at least 21,484 people and 2039 families were displaced from their homes [29].

As a part of post-landslide reconstruction process, 1729 families were relocated into safer settings [30]. The importance of this initiative lies in the fact that it gave the displaced community the options of owner-driven and donor-driven approaches. As a result, total of 211 families have been relocated under the donor-driven approach where total of 1518 families were relocated under the owner-driven approach [30]. Giving options for displaced communities for relocation can be considered vital for several reasons. On one hand, most vulnerable households might not be in a position to opt for the owner driven option as they do not have any other person to engage in construction activities, lack of savings (as the amount they get from the government might be insufficient to complete the house), lack of family labor, etc. However, when officials offer displaced people the option of an owner driven approach, some may prefer opting out as they wish to construct their own house according to their aspirations. One should also be mindful that this might be a journey filled with challenges for a displaced community. Based on the said context, the study was based on an investigation of the owner driven approach to investigate if the expected aspirations had been met or not. In the context of the owner driven approach which was utilized in this project, the following strategies were adopted: 
1. Government Resettlement Site (GRS): A plot of approximately 10 perches of land was allocated by the government for house construction. Beneficiaries were granted Rs. 1.2 million for house construction in five (05) installments based on the stage of completion. Under this initiative 949 families were relocated into GRS settings [31].

2. Individual Resettlement Site (IRS): This option was given to beneficiaries who wished to relocate in their own land. Rs. 4 million was granted to acquire land and Rs. Additionally, 1.2 million was allocated for house construction and 569 families have been relocated into IRS settings.

Out of the above-mentioned settings, to conduct the present study, the following locations were selected and they represent the settings of GRS and IRS in the ownerdriven approach:

- The GRS Setting

This GRS relocation site is located in the Y District Secretariat Division. This location has relocates from different areas who used to live in the $X$ District itself and all respondents of this study were identified as relocates who were affected by the landslide event which took place in 2016. There are 163 housing units in this setting.

- $\quad$ The IRS Setting

The IRS relocation site is located in the Z District Secretariat Division. This location has 25 housing units and 23 of them are relocated housing units. The residents of the said 23 housing units were living in the same neighbourhood prior to displacement in 2016.

The data collection of the present study was twofold where in-depth interviews were conducted with the relocates to inquire of the status quo of their relocated settings and the role of social capital. To achieve these objectives, purposive samples of ten in each setting were selected. The criteria of selecting these households were based on the vulnerable context of each household, i.e., members with chronic illnesses and disabilities. Therefore, the respondents from the GRS setting included respondents who were suffering from severe illnesses such as cancer and who were paralyzed. On the other hand, from the IRS setting a mother with a new born baby and a youth with Down syndrome were notable respondents. In-depth interviews were conducted by a research team of three researchers for two months.

In the second stage, five structured interviews were conducted with project officials and an expert sampling technique was utilized to select the officials who had been handling responsibilities relevant to the relocation process. The main objective of this stage was to inquire into how the relocation process was executed.

The interviews were conducted in Sinhala and later transcribed into English for analysis purposes. The collected qualitative data were analysed using the thematic analysis method where the findings were mapped as to the main themes of impact of relocation and the perception on the relocation. Further, sub themes were recognized as per the model of residential satisfaction of public low cost housing formulated by Mohit, Ibrahim, and Rashid (2010) [23].

\section{Results}

This section will present the research findings based on two thematic orientations of the relocation process and the impact of relocation. The impact of relocation is presented utilizing the thematic orientation of the model of residential satisfaction of public low cost housing formulated by Mohit, Ibrahim, and Rashid (2010) [22]. The thematic mapping of these results has been visualized in the following Table 1: 
Table 1. The thematic mapping of the research findings.

\begin{tabular}{|c|c|c|c|c|c|c|}
\hline & \multirow{3}{*}{$\begin{array}{c}\text { The Relocation } \\
\text { Process }\end{array}$} & \multicolumn{5}{|c|}{ Impact of Relocation } \\
\hline & & \multicolumn{2}{|c|}{ Sheltered Components } & \multicolumn{3}{|c|}{ Non-Sheltered Components } \\
\hline & & $\begin{array}{l}\text { Dwelling Unit } \\
\text { Features }\end{array}$ & $\begin{array}{l}\text { Supporting } \\
\text { Features of the } \\
\text { Dwelling }\end{array}$ & $\begin{array}{l}\text { Public } \\
\text { Facilities }\end{array}$ & Social Environment & Neighborhood \\
\hline IRS & $\begin{array}{l}\text { Main reason to } \\
\text { choose IRS } \\
\text { option was to } \\
\text { have same } \\
\text { neighborhood } \\
\text { as in the } \\
\text { previous land }\end{array}$ & $\begin{array}{l}\text { Elements of the } \\
\text { housing unit: } \\
\text { Not highly satisfy } \\
\text { with the given plan } \\
\text { Monetary } \\
\text { constrains: } \\
\text { Lack of funds to } \\
\text { complete the house } \\
\text { Tricked by the } \\
\text { owner of the lands } \\
\text { that the lands were } \\
\text { not suitable to } \\
\text { build habitats } \\
\text { Ownership of the } \\
\text { housing unit: } \\
\text { Have legal deeds }\end{array}$ & $\begin{array}{l}\text { Lack of proper } \\
\text { electricity and } \\
\text { water supply } \\
\text { Maintenance } \\
\text { should be done } \\
\text { by themselves }\end{array}$ & $\begin{array}{l}\text { Difficult main } \\
\quad \text { road to } \\
\text { pass through } \\
\text { Far away from } \\
\text { the main town }\end{array}$ & $\begin{array}{c}\text { Relationship } \\
\text { among the } \\
\text { relocates: } \\
\text { Positive relationship } \\
\text { due to their same } \\
\text { neighborhood } \\
\text { Relationship with } \\
\text { host community } \\
\text { Have a cordial } \\
\text { relationship } \\
\text { compared to } \\
\text { the GRS } \\
\text { Involvement into } \\
\text { the social } \\
\text { organization } \\
\text { Poor involvement } \\
\text { compared to } \\
\text { GRS setting }\end{array}$ & $\begin{array}{c}\text { Poor accessibility } \\
\text { to the } \\
\text { grocery shop } \\
\text { and hospital } \\
\text { No facilities to } \\
\text { accommodate } \\
\text { their livelihoods }\end{array}$ \\
\hline GRS & & $\begin{array}{l}\text { Elements of the } \\
\text { housing unit: } \\
\text { Not highly satisfy } \\
\text { with the given plan } \\
\text { Ownership of the } \\
\text { housing unit: } \\
\text { Do not have } \\
\text { legal deeds }\end{array}$ & $\begin{array}{l}\text { Have proper } \\
\text { electricity and } \\
\text { water supply }\end{array}$ & $\begin{array}{l}\text { Less difficulty } \\
\text { to pass through } \\
\text { the main road } \\
\text { compared to } \\
\text { IRS setting } \\
\text { Far away from } \\
\text { the main town }\end{array}$ & $\begin{array}{l}\text { Relationship } \\
\text { among the } \\
\text { relocates: } \\
\text { They barely know } \\
\text { each other } \\
\text { Relationship with } \\
\text { host community } \\
\text { Poor relationship } \\
\text { with the host } \\
\text { community } \\
\text { Involvement in the } \\
\text { social organization } \\
\text { Strong involvement } \\
\text { compared to } \\
\text { IRS setting }\end{array}$ & $\begin{array}{l}\text { Poor accessibility } \\
\text { to the } \\
\text { grocery shop } \\
\text { Lack of facilities } \\
\text { to accommodate } \\
\text { their livelihoods }\end{array}$ \\
\hline
\end{tabular}

The above-mentioned findings will be presented in detail as follows under several themes.

\subsection{The Relocation Process}

This section discusses the relocation process of the selected project based on the findings from the key informant interviews. The relocation process was handled by various stakeholders including governmental and non-governmental agencies. The process can be divided into the following three stages:

1. Temporary shelter: This stage took place as soon as the disaster took place. Authorities had taken steps to move the affected communities into relief camps. It was further pointed out that those who were directly affected by the landslide and those who were living in danger hazard prone areas were selected. Public places such as schools, temples, and public grounds were used as camps to temporarily resettle the affected communities.

2. Transitional shelter: Given that permanent relocation takes a considerable amount of time and planning, the next stage focused on providing transitional shelter for 
families who were living in temporary tents. As per the project officials, this stage was assisted by international non-governmental organizations.

3. Permanent shelter: This was the final stage of the relocation process where displaced communities were relocated to several relocation settings.

It is notable that every family that was displaced due to the landslide was made aware about the resettlement options offered by the government during the temporary shelter stage and was given an opportunity to select the option they prefer out of the options mentioned below:

- $\quad$ Resettling in a resettlement site constructed by the government (donor driven).

- Self-Construction of houses with monetary aid provided (owner driven):

o $\quad$ Building a house in their own land with 1,200,000 LKR (GRS)

o Buying land of their choice and building the house; 400,000 LKR for the land and 1,200,000 LKR to build the house (IRS)

"We were given 3 options when we were in the temporary shelter. We thought the IRS option was the best one among them because all of us came from the same neighborhood" Interviewee no. 1, IRS setting

The respondents of the present study preferred to opt for the owner driven approach as they preferred to build their own housing units. The main objective of the respondents who selected the IRS option is noteworthy. As mentioned before, the IRS setting consisted of twenty-three housing units with residents who used to live in the same neighborhood. Their main objective of opting for this option was to live together in the same neighborhood rather than being sent to several settlements. Therefore, they bought land from the same location and continued their previous neighborhood relations post relocation.

"We all agreed to buy this land to live together because we were neighbors from the previous land" Interviewee no. 1, IRS setting

\subsection{Impact of Relocation}

This section will be elaborated based on the conceptual framework of the model of residential satisfaction of public low cost housing formulated by Mohit, Ibrahim, and Rashid [22].

\subsubsection{Sheltered Components}

Sheltered components discuss the housing unit and other facilities connected to the housing units. Hence, this section will discuss the status quo of the housing units of the selected settings.

\section{Dwelling Unit Features}

Housing construction and design were dominantly coordinated by a governmental organization, which developed two manuals for donor driven housing and resilient housing which were granted special cabinet approval.

In terms of the construction of the housing units, as mentioned above, only a sum of 1.2 million was to be given for the construction of the house. Several steps were introduced to release money on an installment basis for the selected beneficiaries to ensure that they utilize the said money effectively when constructing housing units. As per the said steps, there were various aspects of the housing structure which had to be completed and shown to the authorities to secure the next installment. The officials mentioned that this was a fourstep process which ends with the completion of the core house. It was further mentioned that the authorities released a certificate of conformity $(\mathrm{CoC})$ following the completion of all mentioned steps. It was also added that they further recommended retaining 25,000 LKR of the 4th installment and releasing it after obtaining the CoC.

Furthermore, the authorities came up with three suitable housing plans abiding by the resilient housing standards, and the relocates required special permission to deviate from the said plans. A typical housing plan will include the following: 
- $\quad$ Minimum floor area of 650 sq. ft.

- Resilient foundation and a superstructure

- Two bedrooms

- A kitchen

- A permanent roof

- A water seal toilet and a septic tank, and

- Availability of electricity and water [26] (p. 5).

While it is commendable to see the efforts put in by the project authorities to efficiently execute the selected relocation project, the concerns mentioned below were raised by the respondents:

i. Elements of the housing unit plan

Some respondents had a few reservations towards elements such as the number of rooms and the floor.

A common concern raised in both settings was the fact that the toilet and the bathroom were constructed together and situated inside the housing unit. A 20-year-old daughter who resided in a housing unit where the head of the household was paralyzed explained how they changed the plan for her father's convenience in the following manner:

"In our case, according to the given plan, the toilet was situated inside, in the upper floor of the house. But, we made it outside the house to make it comfortable for our father. However, we did not inform the authorities and we have not encountered any issues so far." Interviewee No 1, GRS Setting

ii. Monetary constraints

Respondents from the settings raised concerns about the inadequacy of the amount allocated for them to build the housing units. It was pointed out that many could not completely finish the housing unit without their personal funds.

"First, according to the given plan we built a room and a bathroom. Then we expanded the plan and added some additional rooms. Firstly, a non-governmental organization gave us a model toilet and then we constructed a permanent toilet according to it. So, the given money wasn't enough and I pawned my jewelry and got more money to finish this house. However, within two years we built this house to this extent." Interviewee No 5, IRS Setting

On the contrary, officials mentioned that the allocated amounts were sufficient to build the houses and that the estimation was made in line with the resilient housing features. However, they were of the opinion that people found the allocated amount to be inadequate as they wanted to do alterations to the approved plan.

Due to these monetary constraints, there are several housing units from both settings which are half completed and yet to be fully constructed.

Further, the respondents from the IRS setting explained an added burden in terms of purchasing land. They claimed that the allocated 400,000 LKR was inadequate to purchase suitable land. The residents of the IRS setting believe that they were tricked by the owner of the lands and that the lands were not suitable to build habitats. Respondents consider the location to not be suitable to live in as they are finding it difficult to access the location and to get a stable water supply. However, they are of the opinion that this is the best they could negotiate for the given amount.

iii. Ownership of the housing units

It is notable that all the respondents have ownership of the lands to which they have been relocated. On the other hand, the respondents from the GRS setting are yet to gain ownership and they have been given a government certificate from the relevant authorities. 
Supporting Features of the Dwelling Unit

In terms of the dwelling unit, supporting features such as water and electricity facilities are important for the present study. In the GRS setting, both water and electricity have been duly supplied to the housing units. They have a central water tank in the middle of the setting from which water is distributed among the housing units of the setting.

On the other hand, it is unfortunate that the IRS setting is yet to sort out matters related to water and electricity. The respondents claimed that they do not get proper electricity until $10.00 \mathrm{pm}$ at night and it is a challenge for them to handle household chores due to such electricity constraints. In terms of the concern about water, respondents have been struggling to get a proper motor for them to pump water to their housing units without any disruptions.

"Initially, we had a motor from the government officials and now we are using a motor. However, it does not work properly now. Usually, we have to wait for a longer period for it to be fully filled so that every household will get water through pipelines. At this moment we get water from a tube well which is owned by a neighbor (host community) who lives at the end of the road. He does not charge us." Interviewee No 4, IRS Setting

They further added that an international non-governmental organization had given them large water tanks to collect rain water. However, in their opinion it was not a success. A respondent with a three-month-old infant raised a concern about washing the baby and clothes as she was not in a position to take her infant to the river which is located at the end of their setting.

Moreover, there appears to be less involvement by officials in this matter. The reasoning is that the respondents own the land and thereby they have to sort out such matters by themselves with the relevant government officials to get uninterrupted electricity and water supply facilities.

\subsubsection{Non-Sheltered Components}

This section is an evaluation of the facilities and social networks which function outside the relocated housing units.

\section{Public Facilities}

It is notable that both settings do not have specific public facilities such as a community hall and a playground. In terms of access to the nearest town, the GRS setting is located 2 to $3 \mathrm{~km}$ away from the main road and the IRS location is located 5 to $6 \mathrm{~km}$ away from the main road. In terms of the quality of roads, the roads in the GRS setting are comparatively better in quality than the IRS setting which makes the setting easily accessible.

One of the IRS settings, however, is located on a rock with a deep slope which makes it difficult to access.

"Even three-wheelers do not like to pass our road because it is difficult for them. Once there was an accident too." Interviewee No 1,IRS Setting

Further, respondents were worried about their situation in a time of emergency as it takes time for them to get to the main road due to the geographical characteristics of the setting.

"We have deeds for the lands; only deeds but no other facilities. They first promised to provide a playground for our children but they did not attend to it. There is a huge difference among the intervention of officers when comparing IRS, GRS and donor driven houses." Interviewee No 9, IRS Setting

\section{Social Environment}

When evaluating the social environment, it is vital to inquire into the relationship among the relocates and their relationship with the host community. The relationship among the relocates was considerably positive. While the IRS setting consisted of residents 
from the same neighborhood, relocates were relocated from several locations to the GRS setting. In terms of social organization, it is notable that the IRS setting had no such organization per se while the residents from the GRS setting tended to continue membership of social organizations such as the death donation society formed in their original setting. The respondents did not exhibit a cordial relationship with their host community.

"When we want to buy vegetables or groceries we have to go the nearest town because the retail shop nearby is handled by a host community member and the goods are high in price. Also, we don't interact with the host community here." Interviewee No 6, GRS Setting

Given that the neighborhood remained the same in the IRS setting the respondents did not exhibit any conflict among the relocates except for one special circumstance. The setting has a 64-year-old mother with her 40 years old son who is diagnosed with down syndrome. This diagnosis has labeled them as the 'Pissugedara' (eccentric/crazy house) and their neighbor is in a serious conflict with them in terms of the boundaries of their lands.

Their relationship with the host community is more cordial in comparison to the GRS setting.

"They have been assisting us in various ways. Firstly, they gave us electricity when we were building our houses. Moreover, they helped us with filling water barrels. Right now, a family at the end of the road has a tube well who gives us water free of charge. The family started this after their mother passed away as a good deed in memory of her." Interviewee No 5, IRS Setting

Neighborhood Facilities

In terms of the neighborhood facilities, the GRS setting revealed concerns such as accessing the grocery shop and hospital. They mentioned that they had to travel to the nearest city to buy goods for a reasonable price.

"When we want to buy vegetables or groceries we have to go to the nearest town. Because the retail shop in this village sells goods that are high in price." Interviewee No 2, GRS Setting

In terms of their access to the hospital, a respondent who has been diagnosed with breast cancer said the following:

"I have to go to the hospital for tests and also have to be admitted once a week. We do not have a good hospital nearby which can accommodate medical needs like mine, so I have to go to general hospital located in the neighboring district. Every journey to the hospital costs 3,000 LKR. It is tiring to go by bus to the neighboring district so I have to go in a three-wheeler which costs 3,000 LKR." Interviewee No 4, GRS Setting

On the other hand, respondents from the IRS setting also claimed that they have an issue when accessing grocery stores with reasonable prices and that they have to travel to the main town to do their grocery shopping.

Another vital concern in terms of the neighborhood facilities is the lack of facilities to accommodate their livelihoods. Respondents from both settings had a land-based livelihood and after relocation the new neighborhoods do not approve such livelihoods. They added that even though they are allowed to travel to their original land for agricultural purposes, this requires them to travel 10 to $15 \mathrm{~km}$ to reach those lands and it has a grave impact on their daily expenditure. It was also highlighted that respondents are finding it difficult to maintain their original land as most of their crops are either stolen or destroyed by various animals and people in the neighborhood. The respondents further stressed this has resulted in a dire impact on their financial situation,

"It would have been great if they were mindful of our livelihoods; at least by organizing some training for us to initiate new livelihood strategies in the new setting. I am all alone with three children and have started rolling thin cigarettes as a survival strategy." Interviewee No 1, IRS Setting 


\section{Discussion}

Overall, the GRS participants seemed more satisfied than the IRS participants as they tend to believe that they do not get enough attention of the authorities in comparison with the relocates who opted for GRS. This was further emphasized from the infrastructural constraints the respondents from the IRS are facing in terms of water and electricity. However, social solidarity can be seen among the IRS participants compared to the GRS participants because all of them were neighbors in the previous setting. Even though the present study is based on a small sample which may bring into question the generalizability of the findings, this was an attempt to conduct an in-depth study of the status quo of two different owner driven relocation locations where each respondent was contributing towards various aspects of the impact of relocation.

The discussion of the findings can be made by using various recognized thematic backgrounds. First of all, in terms of a donor driven approach in post disaster relocation, there are several issues in terms of the relocation process and the housing units. Some of such issues can be listed out as follows: quality of the housing units, lack of community participation, and the low quality of the raw materials utilized in construction of the housing units $[32,33]$. However, in relation to the findings of this study it was evident that respondents who resided in donor driven households did not have such concerns as the respondents themselves were a part of the construction process and it was their choice to purchase relevant materials. It has been pointed out that the involvement of the community in the construction process in the owner driven process increases the satisfaction of post relocation housing units $[34,35]$. Further, the relocation project selected for the study requires appreciation for having a solid policy background in place to ensure resilient housing and an execution process. Mortreux et al. [36] have emphasized the necessity of having an adequate policy background in planned relocation.

In the context of housing construction, as per the United States Agency for International Development (2014) [37], the owner driven approach is time consuming, produces unfinished and not so aesthetically pleasing housing units in general. However, as the findings suggests, this donor driven approach assists resettlers to build their house according to their aspirations, although completion is time consuming due to various reasons. Hence, it should be noted that giving options to resettlers is vital rather than forcing them to consider one.

Furthermore, the United States Agency for International Development [38] also adds that owner-driven housing units are not resilient enough. On the contrary, the housing units of the present case study are developed based on the resilient policy developed by project implementing authorities. However, as the findings suggest some respondents had concerns related to plans such as having the washroom and the toilet inside the house. This could have been avoided if the displaced community were involved in the planning process and awareness had been raised on policy strategies as pointed out by Scudder [20].

In terms of the impact of relocation, some of the impoverishment risks explained by Cernea [21] in his conceptual framework of Impoverishment Risks and Reconstruction Model for Resettling Displaced Population are evident. As the respondents in the GRS setting are yet to receive entitlement to their lands, they showed signs of landlessness and homelessness and they are worried as to when they will get the deeds as they possess titles for their previous housing units. Furthermore, as the respondents from the IRS setting have limited access to public facilities, it shows a sign of the impoverishment risk of the lack of access to public facilities. In terms of the role of social capital, given the fact that the IRS setting has the same neighborhood as before and their cordial connection with the host community, signs of re-establishment of the pre-displacement routine culture as explained by Downing and Garcia-Downing (2009) [39] are apparent. On the other hand, relocating as a community is a good strategy to keep their social capital intact. This was further useful for the most vulnerable communities such as people with disabilities and chronic illnesses to make their needs fulfilled with the support of the social network developed in the relocated field. 
Even though Oo, Sinindijo, and Lestari (2018) [12] point out that physical conditions of housing units such as lighting and access to utilities contribute to the satisfaction of post disaster permanent housing, it was observed that the respondents at the IRS setting were struggling to get an uninterrupted water supply and electricity. The respondents also showed signs of the impoverishment of joblessness with the loss of their land incentive livelihoods and such impacts have been commonly cited in related studies [14,40]. Furthermore, it was also notable how the needs of people with disabilities were not considered in planning the physical layouts.

This highlights the recommendation of Scudder [21] to not treat relocation as a one-off event and to perceive it as a process which continues for a long time. Therefore, future research possibilities on the rationales behind the decision of the relocates to continue living in the relocated setting or moving out of the setting due to the infrastructural issues highlighted.

These findings could further be compared in the context of Global South. As per the recent study conducted in Nepal in a post-earthquake context, the need of planning ahead of time rather than treating relocation to be an on-off event and community driven resettlement that prioritize community infrastructure have been pointed out [41]. In this context, the project of the present study lacks long term vision and giving detailed attention towards social infrastructure. On the other hand, in the context of China, it has been mentioned that the social, economic, psychological, physical, and behavioral changes of relocates post-relocation should be considered in the planning. This is another lesson to be learned in the case of the present study where the overall impact of relocation should be considered rather than prioritizing the housing aspect [42].

\section{Conclusions}

Even though there are similarities in terms of the housing units, there was a clear disparity between the GRS and IRS settings in terms of infrastructure and other facilities. There is a disparity in terms of implementation within the owner driven housing units where the respondents of the IRS setting were more vulnerable due to the lack of access to adequate infrastructure. The community will require additional time to overcome these challenges and this will lead to a challenge for the project implementing authority to prevent the relocates from leaving their resettlements and moving back to their disasterprone original settings. Even though they have the title to their lands, that itself has become a barrier for them to request relevant facilities for their setting. Therefore, it could be concluded that there is a disparity in terms of the execution and monitoring process of the two owner driven approaches introduced in this case study. This is in fact a great lesson in general when implementing a planned relocation initiative post disaster displacement. Hence, to prevent this disarticulation, the authors would like to recommend the following. These are in fact vital learning reflections for any post disaster recovery planned relocation contexts:

i. Developing a community awareness and involvement strategy to make relocates adhere to the resilient policy guidelines: It is vital to raise awareness among the displaced communities about the resilient housing policy for them to realize the importance of adhering to the given housing plans. This will make the community realize the logic behind the suggested plans and will also help to obtain more effective consultations from the relevant authorities when making alterations to the housing plans. Further, the authorities should get the community involved in the policy formation process to share the scientific knowledge behind the policy formation and to get the insights of the subjective attributes of the relocates in terms of housing satisfaction. As explained, having a community participatory mechanism in policy formation will avoid instances where relocates modify the plan without the proper guidance of the authorities which might have repercussions in the long run. This will make the authorities get an understanding of the perception of the displaced community in terms of their housing unit in the newly relocated setting. Further, this will contribute towards 
their housing satisfaction on the given plans as it will give them closure to the rationale behind such plans.

ii. Having a mechanism where the authorities can interfere in providing facilities to the IRS setting: Even though it has been pointed out that the owners of the lands should sort out facilities such as water and electricity, the project implementation authorities should intervene and assist them in solving these issues. As discussed under the sheltered components, there was a clear distinction between the facilities provided to GRS and IRS settings. Given that the IRS relocates hold the title to their respective lands, there was minimum intervention from the authorities reported.

iii. Providing further guidance to the displaced communities in finding suitable lands for IRS housing units: It was evident that IRS respondents were finding it difficult to find suitable land. Therefore, it is vital to strategize the existing mechanism where the project implementation authorities assist the displaced communities to select suitable land. The mechanism could be regularized further in terms of access to the lands and considerations of vulnerable communities in the displaced community.

iv. Having financial livelihood strengthening workshops: As apparent in both settings, it is vital to conduct workshops to raise awareness on livelihood strategies that can be established beyond land-based livelihoods. Females also can be empowered by raising awareness of self-employment strategies. As was discussed under the non-sheltered components, participants of both settings mentioned how they are facing difficulties to make a livelihood at the new location and it is one of the main reasons why they have a tendency to go back their previous land.

v. Providing recreational facilities: It is important to provide recreational facilities at the settings such as a community centers, playgrounds, etc. This would be helpful to strengthen the relationship among relocates and the relationship between relocates and the host community as discussed under the findings of the social environment.

vi. Awareness on the construction process: In both settings, as discussed under the sheltered components, most of the families could not complete their houses because of this. They tried to add additional parts to the given housing plan and eventually failed to complete the given housing plan with the minimum requirements. As the allocated amount is inadequate for beneficiaries and there are many unfinished housing units, it is necessary to raise awareness about fund management and to assist them to find relevant materials. The project implementation authorities can have a set of registered authorities and can connect them with displaced communities that have selected the owner driven approach.

Author Contributions: Conceptualization, N.F., A.S. and M.W.; methodology, N.F., A.S. and M.W.; validation, C.M. and C.J.; formal analysis, A.S. and M.W.; investigation, N.F.; resources, N.F., A.S. and M.W.; data curation, A.S. and M.W.; writing-original draft preparation, A.S. and M.W.; writingreview and editing, N.F.; visualization, C.J.; supervision, D.A. and R.H.; project administration, D.A., R.H., C.M. and C.J.; funding acquisition, D.A. and R.H. All authors have read and agreed to the published version of the manuscript.

Funding: This research was funded by Erasmus+ Programme of the European Commission, grant number 2018-1-UK01-KA203-048231 and the APC was funded by the same grant.

Institutional Review Board Statement: The study was conducted according to the guidelines of the Declaration of Helsinki, and approved by the Ethics Review Committee of the University of Huddersfield, United Kingdom (24 May 2019).

Informed Consent Statement: Informed consent was obtained from all subjects involved in the study.

Data Availability Statement: The outputs published during the project are available via: https: / / regardproject.com/portal/index.php/outputs (accessed on 15 September 2021).

Acknowledgments: The REGARD project has been co-funded by the Erasmus+ Programme of the European Commission. The European Commission support for the production of this publication does not constitute an endorsement of the contents which reflects the views only of the authors, 
and the Commission cannot be held responsible for any use which may be made of the information contained therein.

Conflicts of Interest: The authors declare no conflict of interest.

\section{References}

1. International Federation of Red Cross and Red Crescent Societies. World Disasters Report 2020: Come Heat or High Water-Tackling the Humanitarian Impacts of the Climate Crisis Together; IFRC: Geneva, Switzerland, 2020.

2. UNHCR. Global Trends Forced Displacement in 2020; UNHCR: Geneva, Switzerland, 2021.

3. UCLouvain, CRED and USAID. Disaster Year in Review 2020 Global Trends and Perspectives. Cred Crunch 2021, 62, 1-2.

4. CRED and UNDRR. 2020 the Non COVID Year in Disasters: Global Trends and Perspectives; CRED: Brussels, Belgium, 2021.

5. Internal Displacement Monitoring Centre and Norwegian Refugee Council. Grid 2021: Internal Displacement in a Changing Climate; IDMC and NRC: Geneva, Switzerland, 2021.

6. Internal Displacement Monitoring Centre. Disaster Displacement: A Global Review, 2008-2018; IDMC: Geneva, Switzerland, 2019.

7. Asian Development Bank. Disaster Resilience in Asia a Special Supplement of Asia's Journey to Prosperity: Policy, Market, and Technology over 50 Year; ADB: Mandaluyong, Philippines, 2021.

8. Oxfam International \& IPS. Disaster Management Policy and Practice in Sri Lanka: Sharing Lessons among Government, Civil Society and Private Sector; Institute of Policy Studies: Colombo, Sri Lanka, 2007.

9. Amaratunga, D.; Haigh, R.; Hettige, S. Accountability in the Context of Disaster Risk Governance; UNDRR: Geneva, Switzerland, 2019; ISBN 978-1-86218-170-0.

10. UN Office for Disaster Risk Reduction (UNDRR). Disaster Displacement: How to Reduce Risk, Address Impacts and Strengthen Resilience, a Companion for Implementing the Sendai Framework Target (E); UNDRR: Geneva, Switzerland, 2019.

11. Yonetani, M. Mapping the Baseline to What Extent Are Displacement and Other Forms of Human Mobility Integrated in National and Regional Disaster Risk Reduction Strategies? Platform on Disaster Displacement: New York, NY, USA, 2018.

12. Oo, B.L.; Sunindijo, R.; Lestari, F. Users' Long-Term Satisfaction with Post-Disaster Permanent Housing Programs: A Conceptual Model. Int. J. Innov. Technol. 2018, 9, 28-32. [CrossRef]

13. Barenstein, J.D. Housing Reconstruction in Post-Earthquake Gujarat; Overseas Development Institute: London, UK, 2006. Available online: http:/ / www.odihpn.org/documents/networkpaper054.pdf (accessed on 8 December 2021).

14. Fernando, N.; Punchihewa, A.G. Relocating the Displaced: Strategies for Sustainable Relocation; Friedrich Ebert Stiftung: Colombo, Sri Lanka, 2013.

15. Karunasena, G.; Rameezdeen, R. Post-Disaster Housing Reconstruction: Comparative Study of Donor vs. Owner-Driven Approaches. Int. J. Disaster Resil. Built Environ. 2010, 1, 173-191. [CrossRef]

16. ADPC and UNDRR. Disaster Risk Reduction in Sri Lanka: Status Report 2019; ADPC and UNDRR: Bangkok, Thailand, 2020.

17. CRED. EM-DAT: The Emergency Events Database—Universitécatholique de Louvain (UCL)—CRED; Universitécatholique de Louvain: Brussels, Belgium, 2019.

18. Carrión-Mero, P.; Montalván-Burbano, N.; Morante-Carballo, F.; Quesada-Román, A.; Apolo-Masache, B. Worldwide Research Trends in Landslide Science. Int. J. Environ. Res. Public Health 2021, 18, 9445. [CrossRef] [PubMed]

19. Mahani, R.T. Comparative Study of Donor Driven vs. Owner Driven Approach on the Way to "Build Back Better" of Gaza Private Demolished Houses. 2013. Available online: https://library.iugaza.edu.ps/thesis/110082.pdf (accessed on 15 September 2021).

20. National Disaster Relief Services Center. Disaster Situation Report As (2020.01.01-2020.12.31); State Ministry of Internal Security, Home Affairs and Disaster Management: Hong Kong, China, 2021.

21. Fernando, N.; Senanayake, A.; Amaratunga, D.; Haigh, R.; Malalgoda, C.; Jayakody, R. Impact of the disaster-induced relocation process on the displaced communities in Kegalle district, Sri Lanka. Eur. Sci. J. 2020, 16, 33. [CrossRef]

22. Scudder, D. The Future of Large Dams: Dealing with Social, Environmental, Institutional and Political Costs; Earthscan: London, UK, 2005.

23. Cernea, M. Impoverishment Risks, Risk Management and Construction: A model of population displacement and resettlement. In Proceedings of the UN Symposium on Hydropower and Sustainable Development, Beijing, China, 27-29 October 2000.

24. Mohit, M.A.; Ibrahim, M.; Rashid, Y.R. Assessment of residential satisfaction in newly designed public low-cost housing in Kuala Lumpur, Malaysia. Habitat Int. 2010, 34, 18-27. [CrossRef]

25. Tacoli, C. Crisis or adaptation? Migration and climate change in a context of high mobility. Environ. Urban. 2009, 21, 513-525.

26. Loughran, K.; Elliott, J.R. Residential buyouts as environmental mobility: Examining where homeowners move to illuminate social inequities in climate adaptation. Popul. Environ. 2019, 41, 52-70. [CrossRef]

27. Blocher, J. Climate Change and Human Mobility: New Perspectives on Climate and Migration, Displacement and Relocation; United Nations University Migration Network: Tokyo, Japan, 2017.

28. Cernea, M.M. The Economics of Involuntary Resettlement: Questions and Challenges; World Bank: Washington, DC, USA, 1991.

29. SLRCS-Kegalle. Landslide Rescue Operation Lauched in Kegalle Distric; SLRCS-Kegalle: Kegalle, Sri Lanka, 2016.

30. Fernando, N.; Amaratunga, D.; Haigh, R.; Wise, B.; Prasanna, J.; Jayasinghe, N. Life Two Years after Relocation: Status quo of Natural Hazard Induced Displacement and Relocation in Kegalle, Sri Lanka. In Multi-Hazard Early Warning and Disaster Risks; Springer: Cham, Switzerland, 2021. 
31. OCHA. Sri Lanka: Floods and landslides Situation Report No. 2; as of 26 May 2016; OCHA Resident Coordinator's Office Colombo: Colombo, Sri Lanka, 2016.

32. National Building Research Organization. Hazard Resilient Housing Construction Manual: Hazard Resilient Construction Series No. 1; National Building Research Organization: Colombo, Sri Lanka, 2015.

33. Keraminiyage, K.P.; Amaratunga RD, G.; Haigh, R.P. Post Tsunami Recovery Capacity Gaps in Sri Lanka. In Proceedings of the CIB W89 International Conference on Building Education and Research (BEAR), Kandalama, Sri Lanka, 11-15 February 2008.

34. Vithanagama, R.; Mohideen, A.; Jayathilaka, D.; Lakshman, R. Planned Relocation in the Contexts of Natural Disaster: The Case of Sri Lanka; Centre for Migration Research and Development Colombo: Colombo, Sri Lanka, 2015.

35. Unnati. Owner Driven Housing Process Post Earthquake Reconstruction Process: Bhachau; Unnati: Noida, India, 2006.

36. UN-HABITAT. Innovative Approaches for Involuntary Resettlement: Lunawa Environmental Improvement E Community Development Project; UN-HABITAT: Nairobi, Kenya, 2009.

37. Mortreux, C.; Safra de Campos, R.; Adger, W.N.; Ghosh, T.; Das, S.; Adams, H.; Hazra, S. Political economy of planned relocation: A model of action and inaction in government responses. Glob. Environ. Change 2018, 50, 123-132. [CrossRef]

38. USAID. Building Back Housing in Post-Disaster Situations-Basic Engineering Principles for Development Professionals: A Primer Draft; USAID: Washington, DC, USA, 2014.

39. Downing, T.; Garcia-Downing, C. Routine and dissonant cultures: A theory about the psycho-socio-cultural disruptions of involuntary resettlement and ways to mitigate them without inflicting even more damage. In Development and Dispossession: The Crisis of Development Forced Displacement and Resettlement; Oliver-Smith, A., Ed.; School of Advanced Research Press: Santa Fe, NM, USA, 2009; pp. 225-254.

40. Nikuze, A.; Sliuzas, R.; Flacke, J.; Maarseveen, M.V. Livelihood impacts of displacements and resettlement on informal households-A case study from Kigali, Rwanda. Habitat Int. 2019, 86, 38-47. [CrossRef]

41. Displacement Solutions. Lessons Learned from Post-Earthquake Policy in Nepal: Guidance for Further Housing, Land and Property Disaster and Reconstruction from Law and Policy Reform; Displacement Solutions: Geneva, Switzerland, 2019.

42. Li, X.; van Ham, M.; Kleinhans, R. Understanding the Experiences of Relocatees during Forced Relocation in Chinese Urban Restructuring. Hous. Theory Soc. 2019, 36, 338-358. [CrossRef] 